\title{
PERANCANGAN SISTEM APLIKASI MANAJEMEN BIRO WISATA PADA PUTRAS TOUR \& TRAVEL
}

\author{
Muhammad Naufal ${ }^{1}$, Lusi Ariyani ${ }^{2}$, Wita Wulandari ${ }^{3}$ \\ 1,2,3 Teknik Informatika FTIK, Universitas Indraprasta PGRI \\ Jl.Raya Tengah No. 80, RT.1/RW.3,Gedong, Kec. PS. Rebo, Kota Jakarta Timur \\ 1mn.academic0@gmail.com, ${ }^{2}$ lusiariyani0312@gmail.com, ${ }^{3}$ witawullandari@gmail.com
}

\begin{abstract}
ABSTRAK
Pekerjaan manusia yang dahulu dikerjakan masih menggunakan media kertas dan tulis tangan, banyak dibantu dengan adanya teknologi komputer sehingga segala proses media kertas dan tulis tangan menjadi serba komputerisasi. Beban kegiatan rutin seperti pengadaan, pengarsipan dan penjadwalan dapat diminimalisasi dengan menggunakan teknologi informasi seperti sistem informasi berbasis web atau desktop.Putras Tour \& Travel saat ini masih menggunakan media kertas dan tulis tangan dalam pendataan produk, pemesanan produk dan pembayaran produk kemudian untuk laporan di pindahkan ke komputer diketik ke microsoft office atau microsoft excel yang sering di pakai oleh Putras Tour \& Travel sehingga memerlukan waktu sangat lama dalam pencatatan nya karena harus di pindahkan kembali data - data ke komputer melalui microsoft excel.Sehubungan dengan kondisi tersebut, maka muncul gagasan untuk membuat suatu pengembangan yaitu sistem aplikasi berbasis desktop, khususnya yang menyangkut pendataan produk, pemesanan produk dan pembayaran produk yang selalu update, serta mempermudah dalam proses laporan produk, laporan pemesanan produk dan laporan pembayaran produk.
\end{abstract}

Kata Kunci : Perancangan Aplikasi, Manajemen, Biro Wisata, Java, Desktop

\begin{abstract}
Human work that used to be done was still using paper and handwriting media, much helped by the existence of computer technology so that all paper and handwritten media processes became completely computerized. The burden of routine activities such as procurement, filing and scheduling can be minimized by using information technology such as web-based or desktop information systems.Putras Tour \& Travel currently still uses paper and handwritten media in product data collection, product ordering and product payments, then the report is transferred to a computer typed into microsoft office or microsoft excel which is often used by Putras Tour \& Travel so it takes a very long time in recording it because it has to be transferred back to the data to the computer via Microsoft Excel.In connection with these conditions, the idea emerged to make a development, namely a desktop-based application system, especially regarding product data collection, product ordering and product payments that are always updated, as well as simplifying the process of product reports, product ordering reports and product payment reports.
\end{abstract}

Key Word: Application Design, Management, Tourism Bureau, Java, Desktop

\section{PENDAHULUAN}

Pada saat ini, perkembangan teknologi informasi sangat cepat, penyebarannya sangat cepat secara global dan tanpa adanya batasan waktu. Pekerjaan manusia yang dahulu dikerjakan masih menggunakan media kertas dan tulis tangan, banyak dibantu dengan adanya teknologi komputer sehingga segalaproses media kertas dan tulis tangan menjadi serba komputerisasi.

Beban kegiatan rutin seperti pengadaan, pengarsipan dan penjadwalan dapat diminimalisasi dengan menggunakan teknologi informasi seperti sistem informasi berbasis web atau desktop.
Putras Tour \& Travel saat ini masih menggunakan media kertas dan tulis tangan dalam pendataan produk, pemesanan produk dan pembayaran produk kemudian untuk laporan di pindahkan ke komputer diketik ke microsoft office atau microsoft excel yang sering di pakai oleh Putras Tour \& Travel sehingga memerlukan waktu sangat lama dalam pencatatan nya karena harus di pindahkan kembali data - data ke komputer melalui microsoft excel.

Sehubungan dengan kondisi tersebut, maka muncul gagasan untuk membuat suatu pengembangan yaitu sistem aplikasi berbasis desktop, khususnya yang menyangkut pendataan produk, pemesanan produk dan 
pembayaran produk yang selalu update, serta mempermudah dalam proses laporan produk, laporan pemesanan produk dan laporan pembayaran produk.

Berdasarkan uraian dan kondisi di atas maka hasil rancangan tersebut dituangkan dalam bentuk manajemen perancangan aplikasi dengan judul Perancangan Sistem Aplikasi Manajemen Biro Wisata Pada Putras Tour \& Travel Berbasis Dekstop.

Tujuan dari penelitian ini adalah untuk membuat Perancangan Aplikasi Sistem Informasi Manajemen Biro Wisata berbasis Desktop agar memudahkan dalam input data produk, data supir, data pelanggan, data pemesanan produk, data pembayaran produk. "Perancangan merupakan penghubung antara spesifikasi kebutuhan dan implementasi. Perancangan merupakan rekayasa representasi yang berarti terhadap sesuatu yang hendak dibangun. Hasil perancangan harus dapat ditelusuri sampai spesifikasi kebutuhan dan dapat diukur kualitasnya berdasarkan kriteria-kriteria rancangan yang bagus". (Kurniawan \& Herryanto, 2017).

Menurut (Susanto, 2011), perancangan adalah spesifikasi umum dan terinci dari pemecahan masalah berbasis komputer yang telah dipilih selama tahap analisis.

Sistem merupakan sekelompok komponen yang saling berhubungan, bekerja sama untuk mencapai tujuan bersama dengan menerima input serta menghasilkan output dalam transformasi yang teratur. (Kurniawan \& Herryanto, 2017). Sistem adalah kumpulan dari subsistem/bagian/komponen apapun, baik fisik ataupun nonfisik yang saling berhubungan satu sama lain dan bekerja sama secara harmonis untuk mencapai satu tujuan tertentu. (Pratita, 2015). Sistem bisa diartikan sebagai sekumpulan sub sistem, komponen yang saling bekerja sama dengan tujuan yang sama untuk menghasilkan output yang sudah ditentukan sebelumnya. (Mulyani, 2016)

Bahasa Pemrograman Java Merupakan Salah satu dari sekian banyak bahasa pemograman yang dapat 9 dijalankan di berbagai sistem operasi termasuk telepon genggam. (Nofriadi, 2015)
Tiket adalah Dokumen berharga yang harus wajib dimiliki oleh penumpang yang akan melakukan perjalanan menggunakan pesawat udara, dokumen tersebut dikeluarkan oleh perusahaan penerbangan terkait yang bertindak sebagai penangkut transportasi yang didalamnya tercantum syarat-syarat perjanjian antar penumpang dan pengakut perusahaan penerbangan. (Mayasari, 2011)

Manajemen adalah proses perencanaan, pengorganisasian, pengarahan, dan pengawasan usaha- usaha para anggota organisasi dan penggunaan sumber dayasumber daya organisasi lainnya agar mencapai tujuan organisasi yang telah ditetapkan. (Handoko, 2012)

Perancangan dapat diartikan perencanaan dari pembuatan suatu sistem yang menyangkut berbagai komponen sehingga akan menghasilkan sistem yang sesuai dengan hasil dari tahap analisa sistem. (Deddy Ackbar Rianto, Dkk, 2015)

(Rizky, 2011) Mendefinisikan bahwa: Perancangan adalah sebuah proses untuk mendefinisikan sesuatu yang akan dikerjakan dengan mengunakanteknik yang bervariasiserta didalam nya melibatkan deskripsi mengenai arsitektur serta detai mengenai komponen dan juga keterbatasan yang akan dialami dalam proses pengerjaan nya.

Menurut (O'Brien, 2013) menjelaskan bahwa, perancangan sistem adalah sebuah kegiatan merancang dan menentukan cara mengolah sistem informasi dari hasil analisa sistem sehingga dapat memenuhi kebutuhan dari pengguna termasuk diantaranya perancangan user interface data dan aktivitas proses.

\section{METODE PENELITIAN}

Waktu dan Tempat Penelitian

Penelitian dilaksanakan pada Maret 2021 sampai Agustus 2021.Tempat penelitian dalam proses pengumpulan data yang menunjang proses penyusunan Skripsi ini dilakukan di Putras Tour \& Travel, Taman Wisma Asri 2 Jl. Melon IV Blok AA 13 No. 04.

Metode penelitian adalah metode grounded (grounded research) yaitu suatu metode 
penelitian berdasarkan pada fakta dan menggunakan analisis perbandingan dengan tujuan mengadakan generalisasi empiris, menetapkan konsep, membuktikan teori, mengembangkan teori, pengumpulan dan analisis data dalam waktu yang bersamaan. Dalam riset ini data merupakan sumber teori atau teori berdasarkan data. Jadi, dapatlah ditarik kesimpulan bahwa grounded research adalah metode penelitian kualitatif yang mencoba mengonstruksi atau merekonstruksi teori atas suatu fakta yang terjadi di lapangan berdasarkan data melalui analisis induktif.

Metode pengumpulan data yang dilakukan oleh penulis untuk mendapatkan data-data serta informasi untuk mendukung penyempurnaan hasil dari penelitian ini antara lain :

\section{Studi Pustaka (Library Search)}

Pengumpulan data dan informasi dari kutipankutipan buku-buku referensi, situs-situs internet serta hasil laporan dan bahan lainnya yang berhubungan dengan Java, NetBeans, serta informasi yang berhubungan dengan masalah yang akan dibahas dalam tugas akhir ini. Dari bahan-bahan tersebut diambil teoriteori yang dapat dijadikan landasan untuk menganalisa masalah yang diketemukan dalam penelitian.

\section{Studi Lapangan (Field Research)}

Metode ini dilakukan penulis secara langsung untuk mengumpulkan data yang berhubungan dengan Perancangan Aplikasi Sistem Informasi Manajemen Biro Wisata berbasis Desktop. Data-data tersebut penulis kumpulkan dengan cara sebagai berikut :

1. Observasi

Metode ini merupakan metode pengumpulan data yang cukup efektif. Metode observasi adalah pengamatan langsung terhadap suatu objek maupun kegiatan yang sedang berlangsung. Dalam penelitian ini penulis melakukan observasi di Putras Tour \& Travel.

2. Wawancara

Pengumupulan data dengan wawancara ini dilakukan untuk mencari data dan informasi tentang hal-hal yang dibutuhkan dalam penelitian. Wawancara dilakukan dengan lembaga atau instansi yang dijadikan objek penelitian.

\section{HASIL DAN PEMBAHASAN}

Proses Bisnis Sistem Berjalan

Proses bisnis dapat didefinisikan sebagai kumpulan dari proses dan berisi serangkaian aktifitas (task) yang saling berhubungan satu sama lain untuk menghasilkan suatu keluaran yang mendukung pada tujuan dan sasaran yang strategis dari perusahaan Sistem yang berjalan pada Putras Tour \& Travel berupa yang meliputi:

1. Proses Pendataan

Pada proses ini pelanggan datang ke kantor untuk menyerahkan data-data, admin input data pelanggan kemudian admin input data supir, data tiket wisata dan data bus .

2. Proses Pemesanan

Proses ini pelanggan memesan tiket wisata ke admin, admin kemudian mencatat pemesanan pelanggan untuk wisata .

3. Proses Pembayaran

Proses ini admin melakukan proses perhitungan tiket wisata yang di pesan oleh pelanggan. Tahap ini perlu menentukan metode perhitungan pembayaran yang akan diserahkan kepada pelanggan, kemudian pelanggan membayar.

4. Proses Laporan

Proses ini admin membuat laporan data tiket, data pelanggan, data pemesanan tiket dan data supir kemudian diserahkan ke manajer.

\section{Usecase Diagram Sistem Berjalan}

Berikut adalah gambar usecase diagram sistem berjalan admin, pelanggan dan manager.

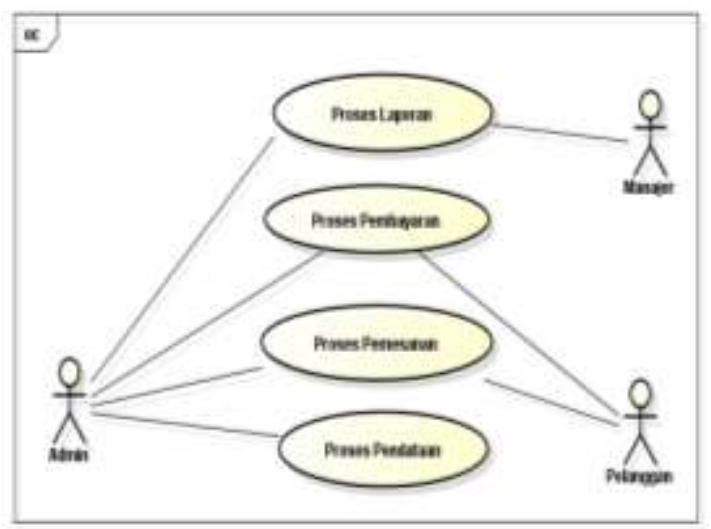

Gambar 1. Usecase Sistem Berjalan. 


\section{Activity Diagram Sistem Berjalan}

1. Activity Diagram Sistem Berjalan Pendataan.

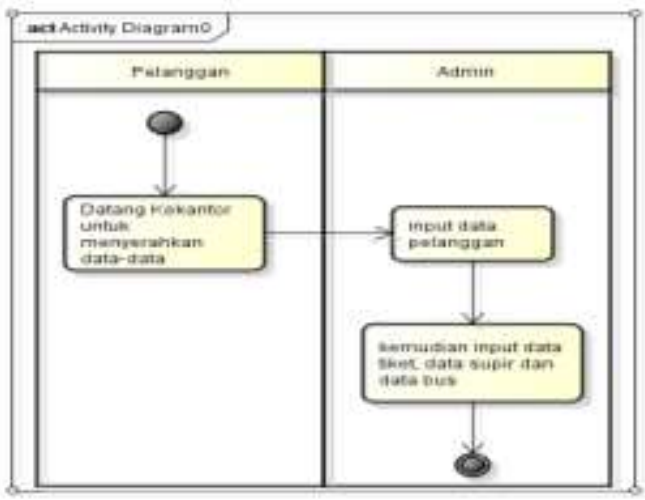

Gambar 2. Activity Diagram Sistem Berjalan Pendataan.

2. Activity Diagram Sistem Berjalan Pemesanan.

Berikut adalah gambar activity diagram sistem berjalan pemesanan, antara pelanggan dan admin

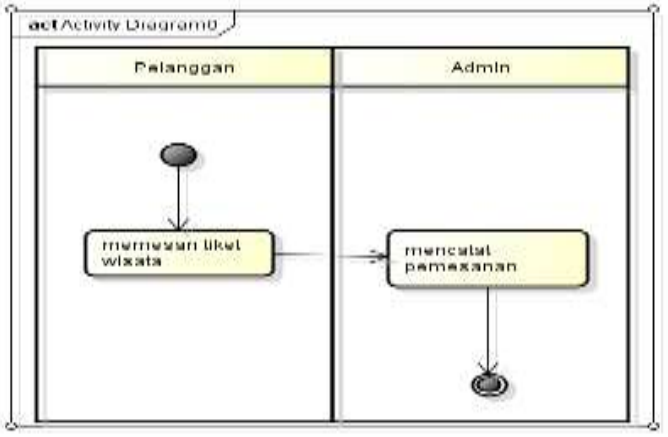

Gambar 3. Activity Diagram Sistem Berjalan Pemesanan.

3. Activity Diagram Sistem Berjalan Pembayaran.

Berikut adalah gambar activity diagram sistem berjalan pembayaran, antara pelanggan dan admin

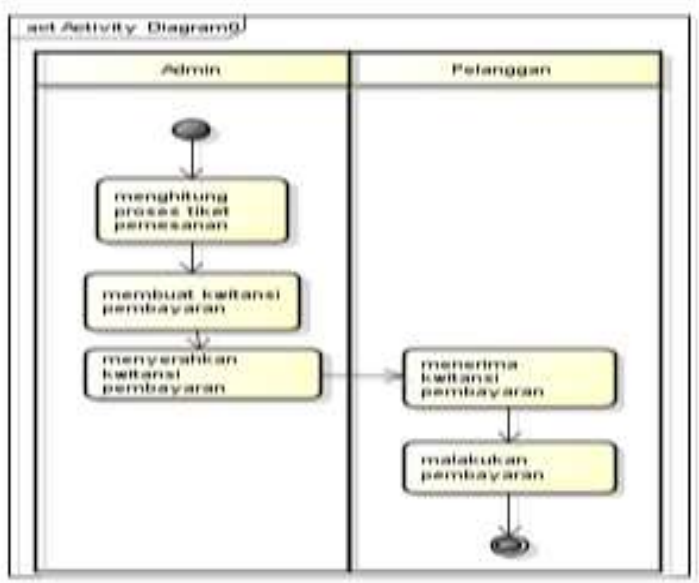

Gambar 4. Activity Diagram Sistem Berjalan Pembayaran
4. Activity Diagram Laporan

Berikut adalah gambar activity diagram sistem berjalan laporan, antara admin dan manager

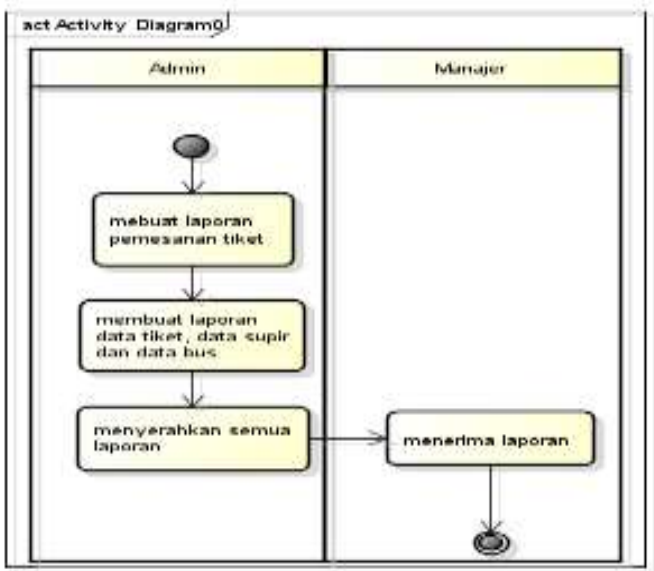

Gambar 5. Activity Diagram Laporan

Unified Modelling Language (UML) Sistem Yang Diusulkan

1. Use Case Diagram

Berikut adalah gambar usecase diagram sistem usulan admin dan manager

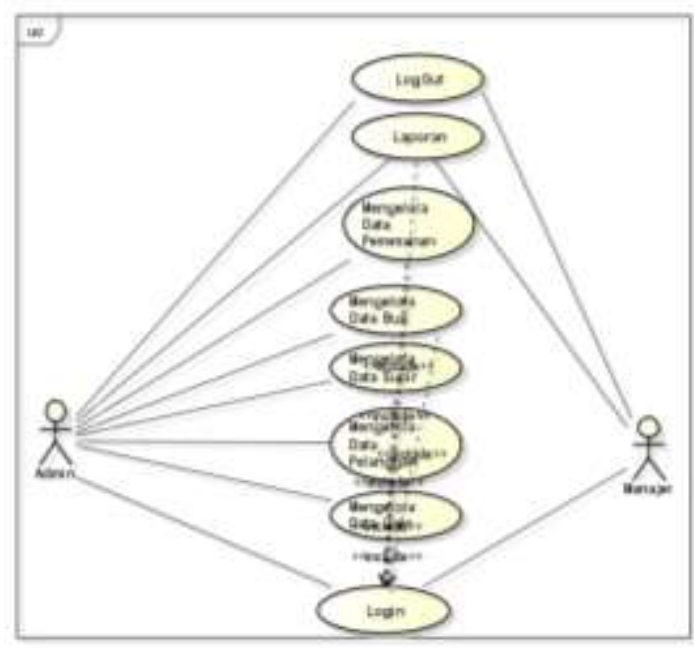

Gambar 6. Usecase Diagram Sistem Usulan

1109 | Perancangan Sistem Aplikasi Manajemen Biro Wisata pada Putras Tour \& Travel 


\section{Activity Diagram}

\section{Activity Diagram Admin}

1. Activity Diagram Admin Login

Berikut adalah gambar activity diagram admin login

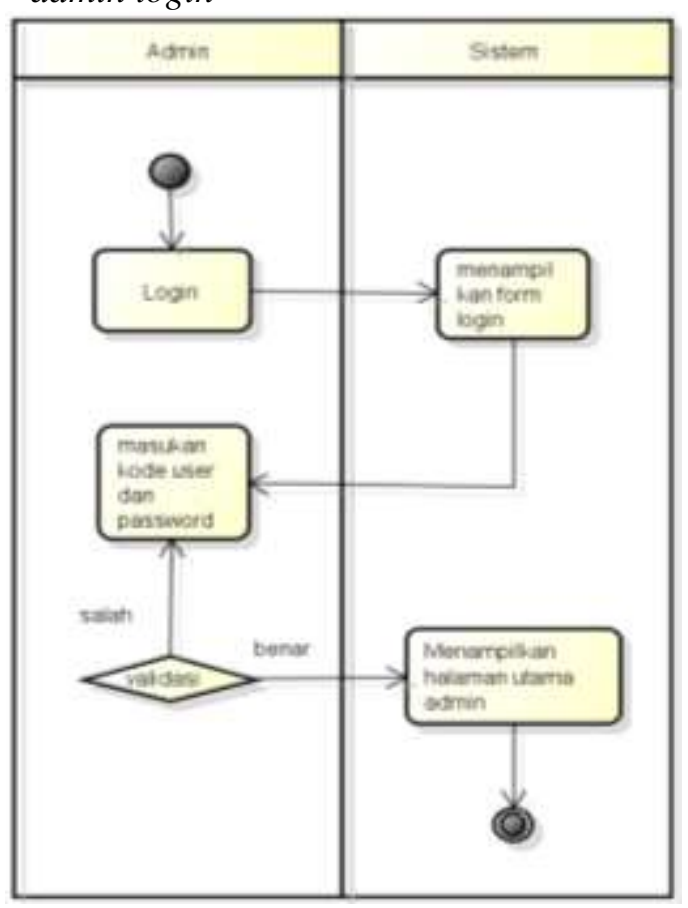

Gambar 7. Activity Diagram Admin Login

2. Activity Diagram Admin Mengelola Data User

Berikut adalah gambar activity diagram mengelola data user

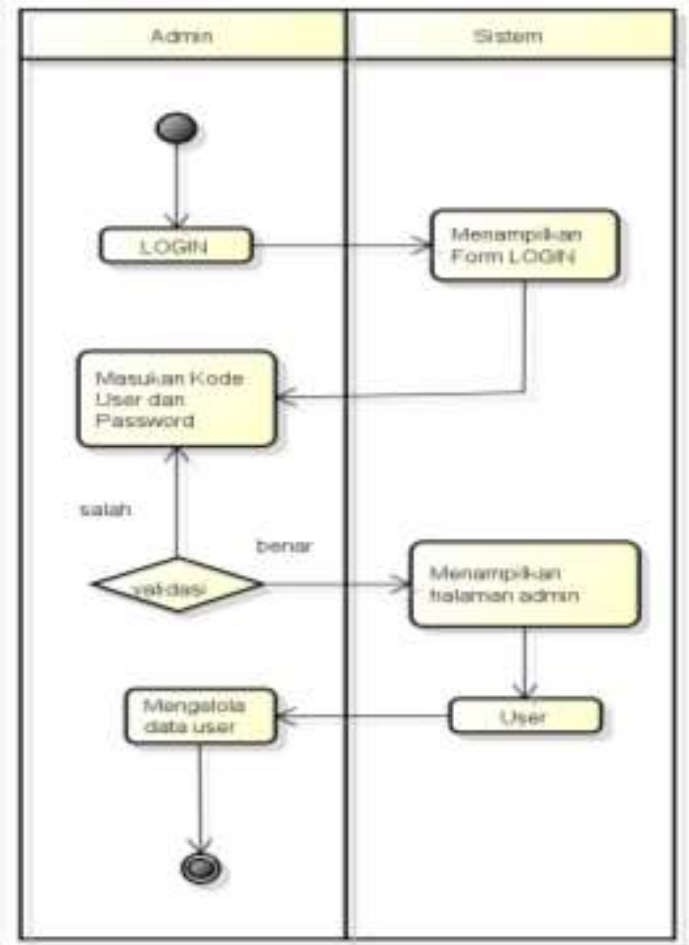

Gambar 8. Activity Diagram Admin Mengelola Data User
3. Activity Diagram Admin Mengelola Data Pelanggan

Berikut adalah gambar activity diagram admin mengelola data pelanggan

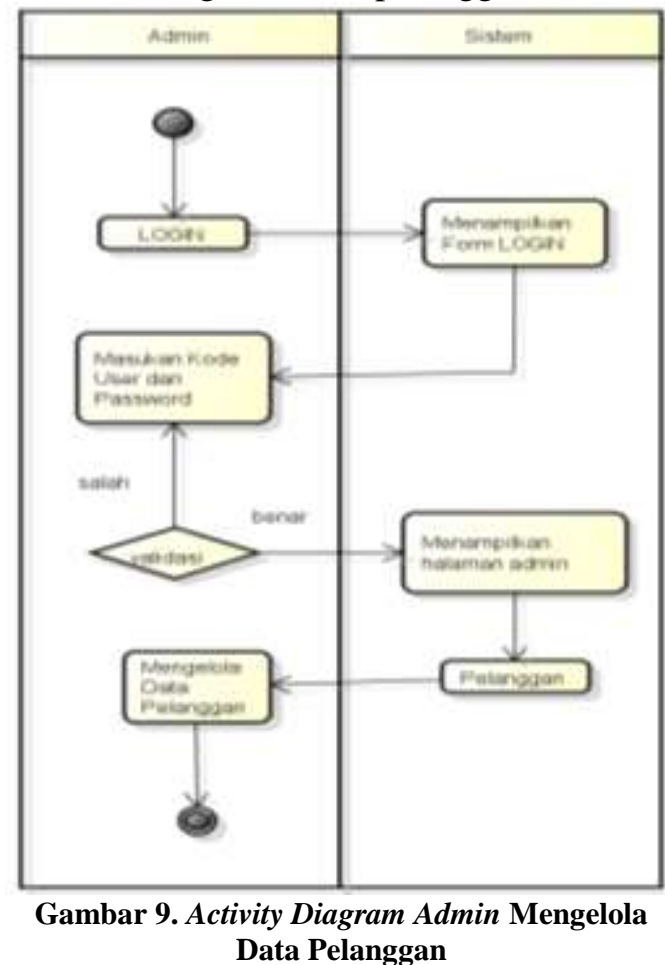

4. Activity Diagram Admin Mengelola Data Bus

Berikut adalah gambar activity diagram admin mengelola data bus

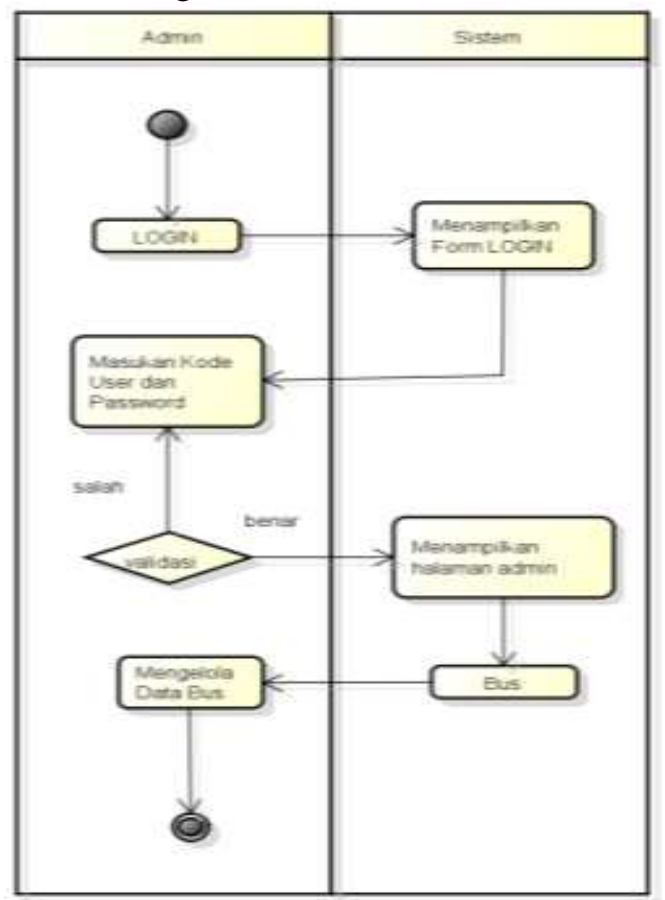

Gambar 10. Activity Diagram Admin Mengelola Data Bus 
5. Activity Diagram Admin Mengelola Data Pemesanan

Berikut adalah gambar activity diagram admin mengelola data pemesanan

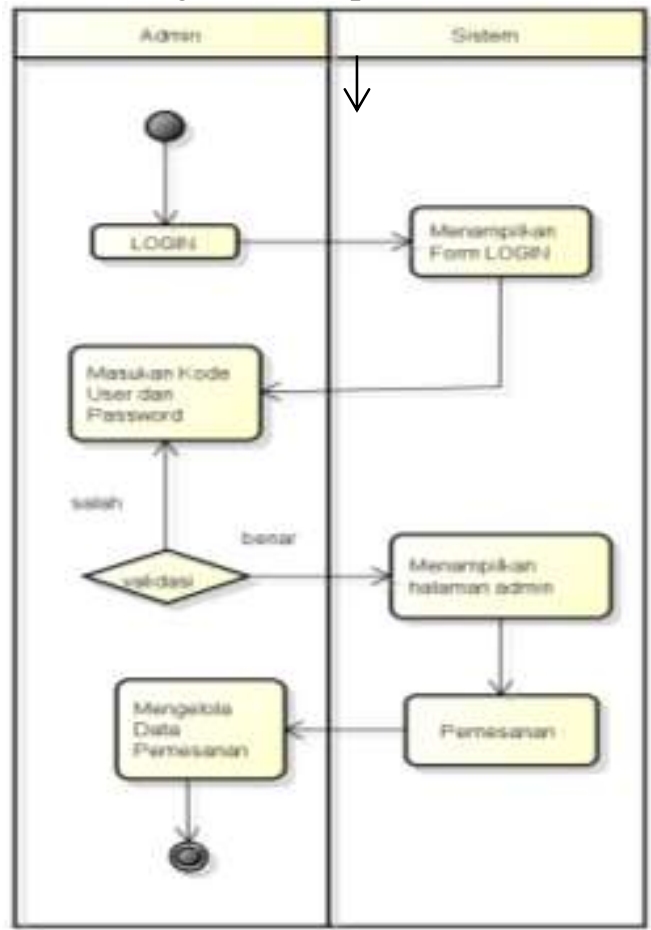

Gambar 11. Activity Diagram Admin Mengelola Data Pemesanan

6. Activity Diagram Admin Mengelola Data Laporan

Berikut adalah gambar activity diagram admin mengelola laporan

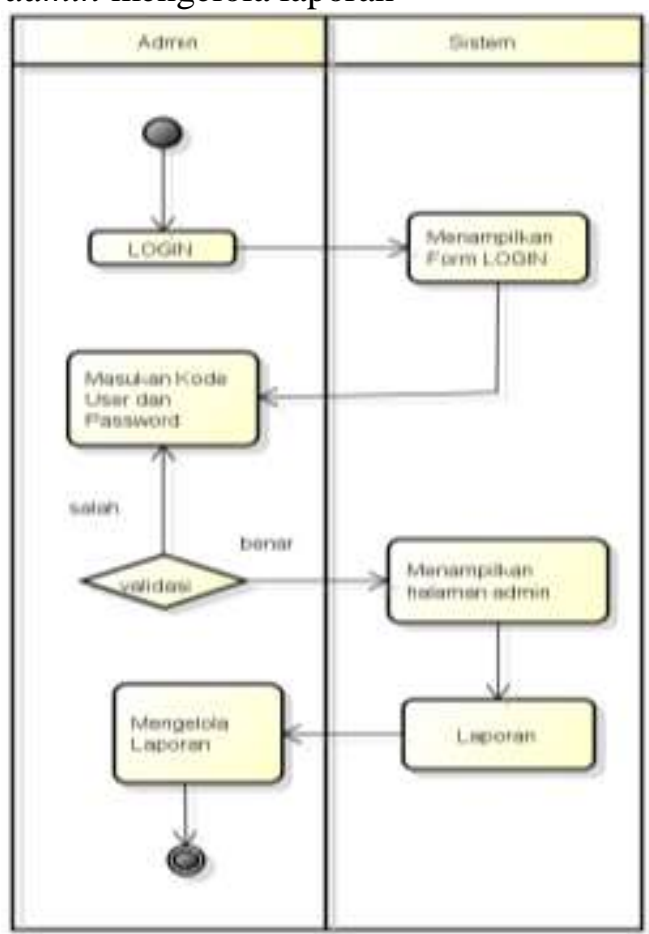

Gambar 12. Activity Diagram Admin Mengelola Data Laporan
Tampilan Layar(User Interface)

Log In

Berikut adalah gambar tampilan login admin dan manager.

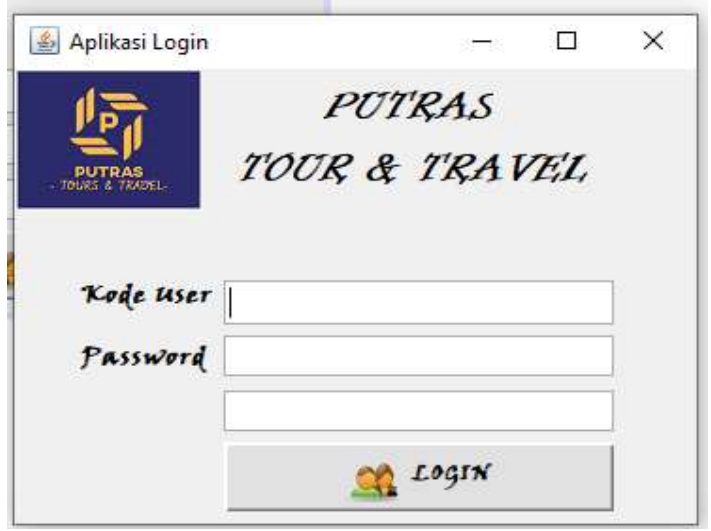

Gambar 13. Rancang Layar Login

Menu Utama

Berikut adalah gambar menu utama admin

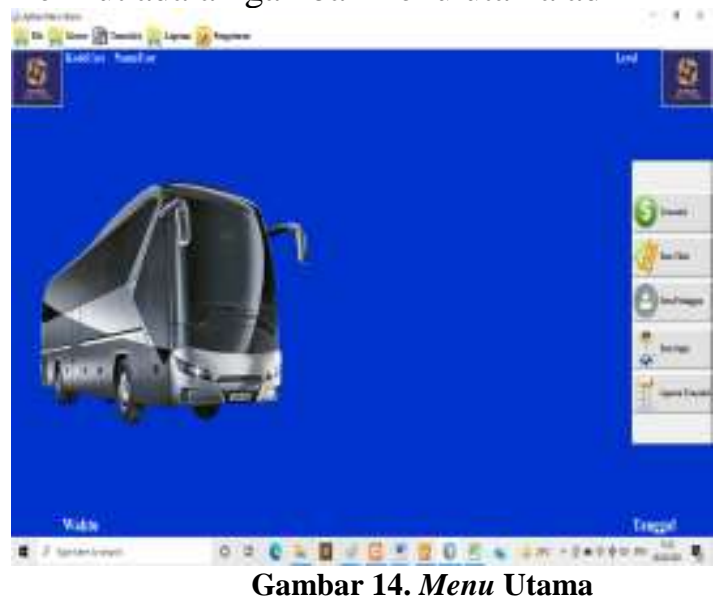

Menu Tiket

Berikut adalah gambar menu tiket yang bisa di akses admin

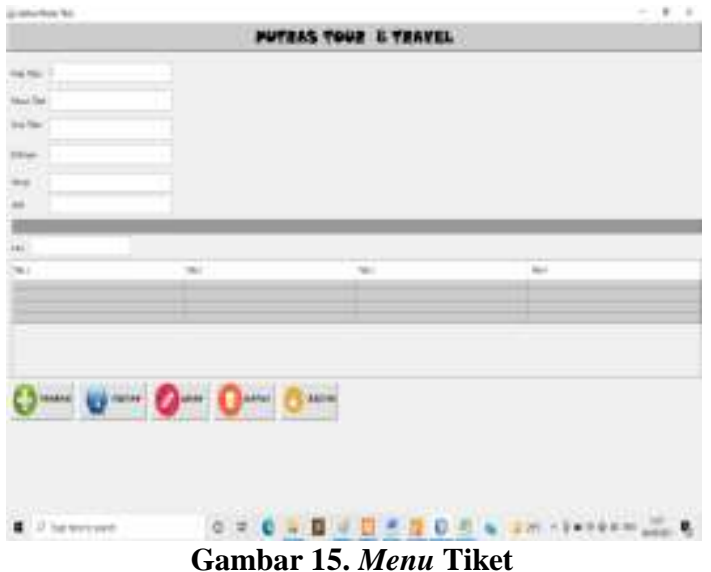


Menu User

Berikut adalah gambar menu user yang bisa di akses oleh admin

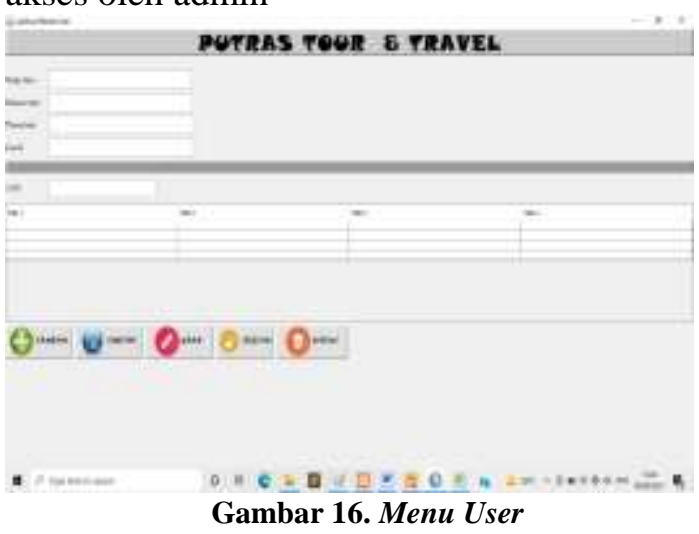

Menu Pelanggan

Berikut adalah gambar menu pelanggan yang bisa di akses oleh admin

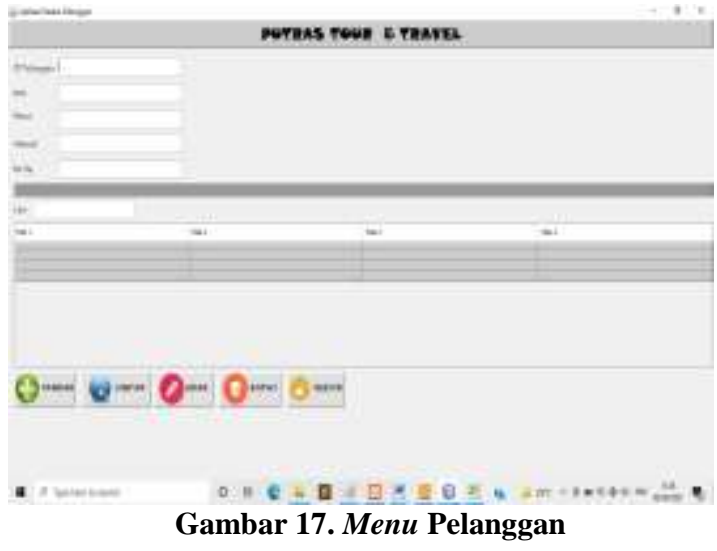

Menu Laporan Pemesanan

Berikut adalah gambar menu laporan pemesanan yang bisa di akses oleh admin

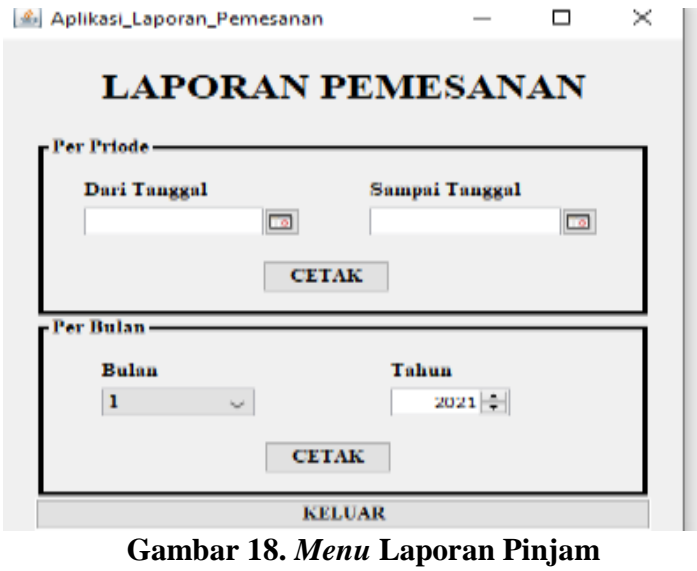

\section{SIMPULAN DAN SARAN}

Berdasarkan kegiatan penelitian yang sudah dilakukan selama perancangan hingga impementasi dan pengujian, maka dapat diambil kesimpulan dari hasil Perancangan
Sistem Aplikasi Manajemen Pada Putras Tour \& Travel Berbasis Desktop sebagai berikut:

1. Aplikasi ini hanya berlaku untuk satu kategori yaitu kasir sebagai admin untuk menembah atau mengurangi data pemesanan dan data tiket yang berada pada program aplikasi ini.

2. Aplikasi ini tidak menangani input data secara online.

3. Adapun beberapa informasi manajemen wisata yang ditampilkan meliputi data pemesanan tiket, data tiket dan laporan harian yang akan diserahkan kepada manajer.

4. Penelitian ini diharapkan dapat membantu dalam mengembangkan pelayanan Putras Tour \& Travel dalam bidang manajemen wisata.

Pada penelitian yang telah dilakukan ini, tentu saja banyak kekurangan dan kelemahannya. Oleh karena itu, terdapat beberapa hal yang perlu diperhatikan untuk membantu dalam pengembangan sistem kedepannya, antara lain :

1. Membantu untuk menyediakan menu pengisian secara online.

2. User interface yang dibangun masih sangat sederhana, sehingga perlu dibuatkan rancangan yang lebih menarik. Misalnya dengan menambahkan animasi pada aplikasi.

3. Sistem aplikasi bisa digunakan untuk admin dan manajer sehingga input data lebih cepat dan pemilik hanya mengecek data penjualan, data permintaan barang, mengcek data barang, data supplier, data user dan laporan.

\section{DAFTAR PUSTAKA}

Deddy Ackbar Rianto, Setiawan Assegaf, E. F. (2015). Perancangan Aplikasi Sistem Informasi Goeografis (SIG) Lokasi Minimarket Di Kota Jambi Berbasis Android. Jurnal Ilmiah Media SISFO, 9(2), 296.

Handoko, T. H. (2012). Manajemen Personalia dan Sumber Daya Manusia. BPFE.

Kurniawan, B., \& Herryanto, D. (2017). Perancangan Dan Implementasi Data Center Menggunakan File Transfer Protocol (Ftp). Perancangan Dan Implementasi Data Center Menggunakan File Transfer Protocol 
(Ftp), 2(2), 91-97.

Mayasari, A. (2011). Sistem Reservation dan

Ticketing PT Sriwijaya Air Distrik Solo.

Universitas Sebelas Maret Surakarta.

Mulyani, S. (2016). Sistem Informasi Manajemen. Abdi Sistematika.

Nofriadi. (2015). Java Fundamental Dengan Netbeans 8.0.2. DeePublish.

O'Brien. (2013). Management Information Systems. McGraw-Hill/Irwin.

Pratita, D. \&. (2015). Bahan Ajar Sistem Informasi Manajemen. Deepublish.

Rizky. (2011). Konsep Dasar Rekayasa Perangkat Lunak. Prestasi Pustaka.

Susanto. (2011). Sistem Informasi Akuntansi. Lingga Jaya. 